\title{
ENTRE O NASCER E O MORRER: CUIDADOS PALIATIVOS NA EXPERIÊNCIA DOS PROFISSIONAIS DE SAÚDE
}

\section{Between birth and death: palliative care in the experience of health professionals

\author{
Entre el nacer y el morir: cuidados paliativos a partir de la experiencia de profesionales \\ sanitarios
}

\author{
Ana Maria Ferreira Alves \\ Programa Força Estadual de Saúde do Maranhão - FESMA - São Luís (MA) - Brasil
}

Maria Lucimeyre Rabelo França

Maternidade Escola Assis Chateaubriand - MEAC/ UFC - Fortaleza (CE) - Brasil

\author{
Anna Karynne Melo \\ Universidade de Fortaleza - UNIFOR - Fortaleza (CE) - Brasil
}

\section{RESUMO}

Objetivo: Compreender como os profissionais de saúde de uma unidade de terapia intensiva neonatal (UTIN), em um hospital-maternidade de alto risco, experienciam os cuidados paliativos neonatais. Métodos: Estudo qualitativo, realizado com método fenomenológico crítico, tendo como instrumento uma entrevista não estruturada, realizada no período de outubro a dezembro de 2015, do qual participaram oito profissionais de saúde da referida UTIN. Surgiram quatro categorias: Experienciando cuidados paliativos; Significando o bebê sem prognóstico; As famílias dos bebês e a afetação dos profissionais; e $\mathrm{O}$ atravessamento da morte na experiência vivida dos profissionais. Resultados: Os principais achados do estudo indicaram que os cuidados paliativos para os profissionais podem ser retratados a partir de diferentes aspectos. Para eles, o olhar e o cuidar dos bebês sem prognóstico estão entrelaçados ao surgimento do envolvimento afetivo; a experiência de contato com a família também aparece como uma forma de serem afetados, pois surgem sentimentos não antes emergentes; e o momento da morte do bebê é um desafio cheio de dificuldades para enfrentar. Conclusão: Percebe-se que, mesmo sem o programa de cuidados paliativos na instituição, existe a iniciativa de realizar uma prática que se aproxima desses cuidados, principalmente ao buscar conforto para esse bebê e maior inclusão da família, o que já mostra sensibilização para tal perspectiva.

Descritores: Unidades de Terapia Intensiva Neonatal; Pessoal de Saúde; Cuidados Paliativos.

\section{ABSTRACT}

Objective: To understand how the health professionals of a neonatal intensive care unit (NICU) in a high-risk maternity hospital experience neonatal palliative care. Methods: Qualitative study carried out using the critical phenomenological method and with the unstructured interview as instrument, performed from October to December 2015, with participation of eight health professionals of the said NICU. Four categories arose: Experiencing palliative care; Giving meaning to the baby with no prognosis; The families of the babies and the affectation of professionals; and Traversing death in the lived experience of the professionals. Results: The main findings of the study indicate that palliative care for the professionals can be portrayed from different aspects. For them, looking and caring for babies without prognosis are intertwined with the onset of affective involvement; the experience of contact with the family also appears as a way of being affected, as feelings that had not emerged before arise; and the moment of the baby's death is a challenge full of difficulties to face. Conclusion: It is perceived that, even without the palliative care program at the institution, there is the initiative to perform a practice that approaches that kind of care, especially with regard to seeking comfort for the baby and greater inclusion of the family, what already demonstrates that they are sensitized awareness to this perspective.

Descriptors: Intensive Care Units, Neonatal; Health Personnel; Palliative Care. 


\section{RESUMEN}

Objetivo: Comprender cómo los profesionales sanitarios de una unidad de cuidado intensivo neonatal (UCIN) de un hospital-maternidad de alto riesgo vivencian los cuidados paliativos neonatales. Métodos: Estudio cualitativo realizado con el método fenomenológico crítico con la entrevista no estructurada como instrumento de recogida de datos realizada en el período entre octubre y diciembre de 2015 en el cual participaron ocho profesionales sanitarios de la referida UCIN. Surgieron cuatro categorías: Vivenciando los cuidados paliativos; Significando el bebé sin pronóstico; Las familias de los bebés y la afectación de los profesionales; y El cruce de la muerte en la experiencia vivida por los profesionales. Resultados: Los principales hallazgos del estudio indicaron que para los profesionales los cuidados paliativos pueden ser retratados a partir de distintos aspectos. Para ellos, la mirada y el cuidar de los bebés sin pronóstico están entrelazados con la aparición del envolvimiento afectivo; la experiencia del contacto con la familia también surge como una forma de ser afectado pues surgen los sentimientos que antes no emergieron; y el momento de la muerte del bebé es un desafio lleno de dificultades para afrontar. Conclusión: Aunque no haya el programa de cuidados paliativos en la institución, se percibe la iniciativa de realizar una práctica que esté cerca de eses cuidados, principalmente al buscar el conforto del bebé y mayor inclusión de la familia lo que muestra la sensibilización para tal perspectiva.

Descriptores: Unidades de Cuidado Intensivo Neonatal; Personal de Salud; Cuidados Paliativos.

\section{INTRODUÇÃO}

A Unidade de Terapia Intensiva Neonatal (UTIN) é destinada à assistência a recém-nascido (RN) - criança com idade de 0 a 28 dias de vida - grave ou em risco de morte, de qualquer idade gestacional, com os seguintes quadros clínicos: dependência de ventilação mecânica, ou que estejam em fase aguda de insuficiência respiratória, com Fração Inspiratória de Oxigênio $\left(\mathrm{FiO}_{2}\right)$ maior que 30\%; pré-termos menores de 30 semanas de idade gestacional, ou com peso menor de 1.000g; necessidade de cirurgias de grande porte, ou pós-operatório imediato de cirurgias de pequeno e médio porte; dependência de nutrição parenteral; e cuidados especializados ${ }^{(1)}$.

A Organização das Nações Unidas apresentou como questão central para os próximos anos a redução da mortalidade na infância, sendo essa uma preocupação para o desenvolvimento do milênio ${ }^{(2)}$. Entretanto, estudos internacionais apontam que, mesmo com desenvolvimento tecnológico impulsionando a sobrevivência de bebês cada vez menores e com complicações clínicas, há ainda casos de mortes inevitáveis, como bebês que nascem com prematuridade extrema ou evoluem para casos incompatíveis com a vida ${ }^{(3)}$.

Em 2016, no Brasil, o número da mortalidade neonatal foi de 24.611. Dentre estes, 6.195 foram explicitados como morte de causas não evitáveis ${ }^{(4)}$. Em relação aos determinantes dos óbitos, prevaleceram a prematuridade, a malformação congênita e as infecções ${ }^{(5)}$.

Os RNs criticamente enfermos podem possuir a morbidade e a mortalidade inerentes à sua condição clínica, o que faz pensar sobre o limite do uso e dos benefícios da tecnologia para com esses pacientes, uma discussão ética que permeia a neonatologia há algum tempo através da filosofia do cuidado paliativo $(\mathrm{CP})^{(6,7)}$. Pacientes prematuros e/ou com baixo peso extremos ( $<27$ semanas e $<750 \mathrm{~g}$ ), que possuem más formações incompatíveis com a vida e que não respondem aos cuidados intensivos, podem ser candidatos ao CP na neonatologia ${ }^{(8)}$.

A perspectiva do CP centra-se na qualidade de vida, no conforto e no alívio dos sintomas físicos do bebê com ameaça à vida, estendendo-se para a diminuição do sofrimento emocional e espiritual da família, com integridade e respeito aos aspectos culturais e crenças espirituais mesmo após a morte do $\mathrm{RN}^{(6,8,9)}$. A assistência possui como princípio que os profissionais se atenham às necessidades do bebê para o tratamento paliativo e às questões da família para realizar o acolhimento merecido, compreendendo que a equipe de saúde também vivencia momentos difíceis ${ }^{(10)}$.

Há um relacionamento intrínseco entre a equipe de saúde, os bebês, a família e o ambiente da UTIN, no qual as relações são afetadas na perspectiva de que o mundo é o campo de experiência do homem, caracterizando um homem mundano, que constitui o mundo e é constituído pelo mundo ${ }^{(11)}$. Essa concepção supera a ideia de dicotomia e neutralidade nas relações no campo da saúde ${ }^{(12)}$, o que implica em os profissionais de saúde da neonatologia serem parte da UTIN e esta, ser parte dos profissionais, não sendo possível dissociá-los. Admitindo-se, portanto, uma multiplicidade de contornos que os envolvem, como aspectos sociais, históricos, culturais e biológicos, dentre outros que permeiam esta constituição $0^{(11)}$.

A menção da fenomenologia na saúde problematiza o conceito de produção de saúde no âmbito da saúde coletiva, olhando para a relação saúde-doença ${ }^{(12)}$, e fortalece a humanização dos serviços de alta complexidade, promovendo o encontro interhumano de profissionais, usuários e familiares ${ }^{(13)}$, perspectivas que corroboram com a filosofia do $\mathrm{CP}$.

No presente estudo, intencionou-se, especificamente, compreender a experiência vivida de profissionais de saúde de uma unidade de terapia intensiva neonatal, a partir da perspectiva fenomenológica crítica. Percebe-se que não há um programa de $\mathrm{CP}^{(14)}$, apesar de o perfil da maioria dos bebês que se hospitaliza aproximar-se dos descritos como elegíveis a esses cuidados. Casos como os de neonatos prematuros extremos e/ou com malformações que sobrevivem com o suporte da UTIN, entretanto, 
com sequelas sérias que os tornam dependentes da alta tecnologia para que sua vida perdure, o que leva ao questionamento se não está ocorrendo apenas uma postergação da morte neonatal para outro momento da vida da criança, sem considerar sua dignidade e qualidade de vida ${ }^{(15)}$. Reflete-se ainda no cenário atual da saúde do país, mobilizando-se em implementar políticas públicas de atenção à primeira infância, que visam à promoção de saúde a partir do cuidado integral, desde a gestação ${ }^{(16)}$.

Assim, a relevância deste estudo está, pois, em instigar os CPs dentro deste contexto, entendendo que objetivar qualidade de vida e bem-estar do bebê com uma condição clínica ameaçadora da vida é promoção de saúde. Para o campo da saúde coletiva é fundamental que se possa discutir os aspectos subjetivos envolvidos na relação morte, CP e as experiências dos profissionais, pois esses profissionais, muitas vezes, ficam fragilizados diante da situação de morte de um bebê, o que torna a temática uma preocupação de saúde dos profissionais que lidam com o enfrentamento dessa condição e as limitações do saber e fazer em saúde.

Como parte dessa perspectiva, deve-se ter uma atenção diferenciada para o profissional que lida com a morte e o entendimento acerca dos CPs, para que esses possam desenvolver da melhor forma o cuidado na UTIN ${ }^{(10)}$. Assim, questiona-se: No seu processo de cuidado do bebê em uma UTIN, como você experiencia os cuidados paliativos na neonatologia?

Diante desse contexto, objetivou-se compreender como os profissionais de saúde de uma unidade de terapia intensiva neonatal (UTIN), em um hospital-maternidade de alto risco, experienciam os cuidados paliativos neonatais.

\section{MÉTODOS}

Trata-se de estudo qualitativo realizado entre outubro e dezembro de 2015, justificado pelo objetivo de compreender os CPs na experiência vivida do profissional de saúde de uma UTIN. As pesquisas qualitativas visam apreender os fenômenos e todas as dimensões humanas neles envolvidas, que não podem ser estipuladas em variáveis e analisadas por estatísticas ${ }^{(17)}$. Viabiliza-se pensar em desafios nas práticas de saúde coletiva, focando em estudos de processos humanos, desvencilhando-se do acúmulo da biotecnologia ${ }^{(18)}$.

Delineou-se esta pesquisa qualitativa como um estudo de campo, que ocorreu em um hospital-maternidade situado na cidade de Fortaleza, capital do Estado do Ceará, classificado como nível de atenção terciária, referência em gestação de alto risco, atuando como Centro de Apoio às Boas Práticas em Atenção Obstétrica e Neonatal no Nordeste do Brasil e com a titulação de Hospital Amigo da Criança. O serviço de Neonatologia da instituição é constituído pelos setores UTIN - duas unidades - e Unidade de Cuidado Intermediário Neonatal (UCIN) - três unidades -, totalizando 56 leitos para os bebês ${ }^{(19)}$.

Os participantes da pesquisa foram os profissionais de saúde das UTIN do referido hospital, sendo um de cada categoria da equipe, assumindo a existência das particularidades de cada núcleo de atuação. Como critério de inclusão, estipulou-se ser profissional diarista do setor UTIN e, como exclusão, profissionais em processo de formação acadêmica ou em pósgraduação. Devido à rotatividade dos serviços, totalizaram oito participantes: um neonatologista, um enfermeiro, um fisioterapeuta, um terapeuta ocupacional, um psicólogo, um assistente social, um farmacêutico e um técnico de enfermagem, os quais foram entrevistados a partir de um convite ocorrido por contato direto da pesquisadora com os profissionais, para participarem da pesquisa.

Para acessar a experiência vivida dos profissionais de uma UTIN, apropriou-se do método fenomenológico crítico a partir da perspectiva de Merleau-Ponty, o qual permite entender que não há uma verdade absoluta na ciência, sendo um movimento que está em constante gênese ${ }^{(20)}$. Existem diferentes prismas da realidade nas experiências diversas, o que leva à compreensão de que a pesquisa não busca um conceito pronto, mas a revelação de prismas. Esse método é uma forma de acessar o fenômeno na experiência vivida do participante ${ }^{(20)}$. O vivido é definido como aquilo que acontece anterior à reflexão. É a reação imediata, antes mesmo do conceituar sobre ${ }^{(21)}$. O objetivo deste estudo foi compreender a experiência dos profissionais, e não o conceito teórico aprendido por eles. Portanto, utilizou-se como instrumento de coleta de dados a entrevista não estruturada, composta de uma pergunta norteadora ${ }^{(21)}$ : "No seu processo de cuidado do bebê em uma UTIN, como você experiencia os cuidados paliativos na neonatologia?". As entrevistas foram agendadas previamente com os colaboradores e aconteceram na própria instituição, em locais silenciosos e privativos. Essas foram gravadas e transcritas, resguardando o anonimato deles.

Há um entrelaçamento dos pesquisadores com os participantes da pesquisa, e, para compreender a experiência vivida por eles, realiza-se a redução fenomenológica nas entrevistas e análise dos dados (até a última etapa), que é a suspensão dos " $a$ prioris", ou seja, é o momento de deixar suspensos os préconceitos e a familiaridade com o mundo para compreender o mundo vivido do outro $^{(11)}$. O que a diferencia da neutralidade é a ciência de que é impossível uma redução completa, pois se está enraizado no mundo, de modo que será sempre uma tentativa ${ }^{(11)}$.

Sem objetivar uma síntese dos significados, realizou-se a análise dos dados em três momentos diferentes ${ }^{(20)}$ : divisão do texto nativo (transcrição das entrevistas) em movimentos; análise descritiva do significado emergente do movimento; e "sair dos parênteses", articulando a experiência vivida dos profissionais com o caminho teórico realizado a partir do que emergiu nas entrevistas, quando se permitiu um posicionamento das pesquisadoras.

A partir da leitura do texto nativo e da sua divisão em movimentos, conforme proposta metodológica ${ }^{(20)}$, elencaram-se os seguintes temas emergentes: Vivência em CP na neonatologia; CP pediátrico e adulto; Possibilidades de assistência em CP na 
neonatologia; Prática de CP na neonatologia da instituição; Viabilidade do bebê; Relação profissional - família; Comunicação de más notícias à família; Lidar com a morte; Autocuidado e cuidado em relação à morte; Dinâmica de trabalho na maternidade; Condição de trabalho; Atuação em outros contextos; Percurso de formação; Relação com a equipe; Experiência pessoal.

Com os temas emergentes, agruparam-se em categorias a partir das afinidades ao objetivo do estudo ${ }^{(20)}$ : Experienciando cuidados paliativos; Significando o bebê sem prognóstico; As famílias dos bebês e a afetação dos profissionais; $\mathrm{O}$ atravessamento da morte na experiência vivida dos profissionais.

Ressalta-se que esta pesquisa respeitou à Resolução 466/2012 do Conselho Nacional de Saúde, que trata de pesquisa envolvendo seres humanos, com aprovação do Comitê de Ética e Pesquisa (CEP) da instituição pesquisada sob o Parecer n. ${ }^{\circ}$ 1253641. Os participantes assinaram o Termo de Consentimento Livre e Esclarecido. A fim de manter o anonimato, atribuíramse nomes fictícios aos participantes: Gabriela, Clara, Laís, Victória, Samile, Jasmim, Paloma e Ana. Esses foram escolhidos por uma das pesquisadoras, remetendo a nomes de crianças, sem identificá-las, que passaram em sua trajetória profissional e vieram a falecer por condições clínicas em que a morte estava inerente, com a intenção de homenagear-se a existência delas no mundo.

\section{RESULTADOS E DISCUSSÃO}

Aqui se apresentam as categorias que emergiram do estudo, discutindo-as a partir dos trechos de falas do texto nativo e articulando-as teoricamente.

\section{Experienciando cuidados paliativos}

Nesta categoria, apresenta-se a experiência vivida em CP pelos participantes através dos seus próprios entendimentos em relação a esses cuidados.

Os CPs são retratados com diferentes vivências: cuidados rotineiros, cuidados na iminência de morte e medidas de alívio da dor:

"Mas os CPS que você diz são em relação ao bebê não é? [...] não, é... (pausa) os CPs não é... Bem dificil [...] não, assim, (pausa) o que a gente, quando eu, você fala em CP, eu me lembro, me vem à cabeça uma pessoa que está em estado terminal não é, você faz só CP não é, faz só medidas de conforto para aquela pessoa não sentir dor não é, mas assim, vou falar de uma forma geral, porque aqui com os bebês é, a maioria dos bebês, pelo menos existe uma chance grande dele sobreviver" (Samile).

Tratando-se de CP, é comum lembrar-se muitas vezes dos idosos que estão no fim da vida, pelo fato da crença que crianças não devem morrer antes de adultos ${ }^{(22)}$. Viu-se isso na fala de Samile, acerca de como vivencia os CPs neonatais. Para ela, CPs são feitos para dar conforto na fase terminal, para não sentir dor, ao mesmo tempo, ela se contradiz, quando menciona que os bebês terão uma chance grande de sobreviver, mesmo sendo crianças de UTIN.

É cabível diferenciar os "cuidados de final de vida" de "cuidados paliativos". Cuidados de final de vida representam a última etapa, quando a morte se torna irreversível, e é uma fase integrante dos $\mathrm{CP}^{(23)}$.

Como outro movimento, os participantes discorreram sobre suas vivências em CP na UTIN acontecendo a partir da equipe e do processo de enfrentamento da família:

"Na minha pouca experiência em trabalhar dentro de uma UTIN, é... Aqui nesse hospital, assim, os poucos bebês que necessitaram CP é, foi de muita importância para a qualidade de vida daquela criança [...] e a gente realmente fazer o que é possivel por aquele bebê, é muito importante dar certo conforto na vida" (Ana).

"Eu acho que CP na neonatologia é algo que a gente acaba tendo certa resistência, certo? [...] e além da resistência dos profissionais existe uma resistência das famílias, não é?" (Laís).

As vivências relatadas aproximam-se da definição desse cuidado, na semelhança de ter uma abordagem ativa que é centrada na qualidade de vida da criança ${ }^{(8)}$. Entretanto, há uma resistência relacionada à própria condição de desenvolvimento da criança, que implica em constantes mudanças, o que torna difícil para a equipe e a família aceitarem o prognóstico limitado ${ }^{(24)}$, sendo necessário aos envolvidos (equipe assistencial e família) possuírem conhecimento acerca do processo de morrer do bebê, compreendendo o "como, onde e porque"(6,25).

Os profissionais explicitaram possibilidades de atuação em CP: a ampliação das visitas, a inclusão da família e da religião, e a necessidade de uma estrutura com um protocolo:

"Mas, assim, na minha pouca experiência nesse periodo, que é qualidade mesmo do que você pode fazer, enquanto esse bebe está aqui não é? É já teve situação de vir pastor, o médico falou da gravidade mesmo e aí a gente apoiar esse processo [...] então, assim, de entrar tia, entrar outros, outras pessoas da família, irmão, pastor, essas coisas" (Clara).

"Eu acho que tinha que ter uma estrutura, que tinha que ter uma equipe mesmo, envolvida no processo, não é, em que (pausa) primeiro pra classificar, ver que paciente entraria nisso, que paciente entraria no protocolo, como é que se faria, que abordagem se faria; eu acho que a gente precisa ter tudo formalizado e precisa de gente que faça isso com a delicadeza necessária" (Laís). 
Há ênfase na qualidade do fazer na proximidade da morte, uma expansão das formas de atuação, corroborando a literatura, que aponta que a assistência deve ser focada nas necessidades do bebê e da família, fornecendo o suporte demandado por eles, incluindo o espiritual, dimensão importante neste contexto ${ }^{(6,15)}$, bem como a permanência dos pais junto aos bebês no fim da $\operatorname{vida}^{(22)}$.

É fundamental ser disponibilizado espaço não só para familiares, mas também para os profissionais manifestarem a afetação da vida e da morte da criança ${ }^{(25)}$. Também se aponta a importância de uma equipe específica para gerenciar os CPs e os profissionais usufruírem desse apoio ${ }^{(9)}$, visto as próprias demandas nas falas e a não formação específica, como evidenciado.

As práticas de CPs no hospital-maternidade investigado, atualmente, sinalizam que não há especificidade na prática de CP, entretanto, explana-se sobre estar havendo uma reflexão no limite do viável:

\begin{abstract}
"Por isso que eu estou te dizendo. Os CPs assim, paliativos mesmo, eu não sei se aqui na neo se aplica essa questão 'não vamos tentar mais', porque não é viável, porque aqui, pelo o que eu vejo, é tentado até sempre, até a gente ver que o bebê não volta, entendeu? Assim, o paliativo nosso é dar um pouquinho mais de qualidade de vida, mas assim, ainda quando para é tentado, é tentada a reanimação" (Ana).

"Nesses últimos tempos, eu acho que isso tem crescido, a gente tem visto vários pacientes em que a gente tem começado a discutir isso, pacientes em que a gente sabe que são inviáveis, que tem uma síndrome genética que é incompatível com a vida, e a gente tem começado a falar a respeito, conversar com as famílias, a mostrar que existe um limite no cuidar, que existe um limite no que se pode fazer" (Lais).
\end{abstract}

O limite do viável traz o questionamento do que é a vida e a forma de viver dessas crianças. A fenomenologia engloba uma complexa discussão sobre a existência humana - que não se pretende alcançar neste estudo - pertinente de ser aqui apontada, por promover o entendimento que a vida existe imbricada à morte, permitindo uma compressão ampliada da finitude. Anterior à essência de quem é o participante, há as condições da existência deste ${ }^{(26)}$. Remete-se a pensar na vida-morte do bebê, como ele se encontra na UTIN, amparado por tecnologias e procedimentos que causam desconfortos, e, nesse contexto, como se constitui a relação com mundo e até em como afeta os pais e as famílias, base da filosofia do $\mathrm{CP}^{(27)}$.

Acerca da implementação dos CPs na neonatologia, é imprescindível uma diretriz que uniformize a prática com critérios de elegibilidade de pacientes, com parâmetros estabelecidos, com condutas a serem realizadas, com passos a serem seguidos, dentre outros. É necessário o planejamento, o treinamento e o envolvimento de todos os participantes, desde a equipe da assistência ao pré-natal, passando pela gestão, até a família ${ }^{(9,27)}$.

Para admitir a especificação de CP na neonatologia, devem ser validadas as barreiras e facilidades que os profissionais de saúde vivenciam, além do conhecimento técnico. Essa é uma filosofia que pode provocar uma autorreflexão no profissional em vários aspectos, pois envolve suas crenças, seus valores e sua cultura, quando deparados com a possibilidade de óbito ${ }^{(10)}$.

\title{
Significando o bebê sem prognóstico
}

Nesta categoria, emergiu uma discussão sobre esses bebês, retratando como os profissionais percebiam e os concebiam e como era cuidar deles, atribuindo diferentes significados.

Os trechos a seguir descrevem o cuidar de bebês sem prognóstico de duas formas diferentes: como aqueles que são evitados e como os que são cuidados como qualquer outro:

“[...] eles são os últimos a serem prescritos; eles são os últimos a serem examinados; eles são os que os residentes não querem ver; eles são os que sobram; eles são escondidos de nós mesmos e isso não são só os médicos, eu acho que tudo meio que passa por aí, não é? É aquela, aquela dor que ninguém quer ver, não é?" (Laís).

"Eu continuo cuidando do mesmo jeito, como outro que poderia ter muitos anos de vida, porque ali é uma vida, não é? Então a gente tem que dar o melhor pra ele enquanto ele viver, enquanto ele estiver ali. Não estou dizendo que "ah, ele vai morrer amanhã", de jeito nenhum, eu não penso assim, porque ele não vai ter uma vida, eu não vou fazer isso, Deus me defenda de uma coisa dessas, porque é uma vida e como deve ser lidado, como um ser humano mesmo que poderia viver muitos, muitos anos..." (Paloma).

Evitar o bebê pode ser uma forma de negar a existência daquele bebê. Questiona-se o cuidar como qualquer outro bebê, se não seria uma negação da condição da morte inerente dele. A negação da morte pode acontecer quando há um prolongamento da vida, na tentativa de controlar a morte e fugir do sofrimento advindo por esta ${ }^{(28)}$, ou mesmo quando, naqueles cuidados, não é considerada a individualidade da situação clínica em que a morte está imbricada. O negar é um mecanismo de defesa transitório saudável, pois não se sustenta encarar a morte o tempo todo, principalmente os profissionais da saúde, sendo problemático cristalizar esse negar ${ }^{(29)}$.

Os participantes descreveram os aspectos imbricados a essa experiência: colocar-se no lugar dos pais, sentimento pelo bebê, presença do bebê, dentre a multiplicidade de significados existentes:

"[...] então, eu fico penalizada; não me atrapalha no trabalho, não me impede de trabalhar, mas eu tenho, eu fico penalizada pela mãe, pelo bebê...” (Samile). 
"Mas, para mim, o que tem ficado muito claro é que, enquanto o bebê está lá, você tem que dar sua atenção, seu cuidado, seu toque, a sua esperança [...]” (Clara).

O conceito de humanização na saúde coletiva através da fenomenologia diz respeito a esse entrelaçamento profissionalusuário, tornando impossível a neutralidade nas relações de saúde. Há uma compreensão do encontro profissional-usuáriomundo constituindo o processo de cuidado, que não é centrado na doença ${ }^{(12)}$. A humanização na UTIN possibilita o encontro entre profissional e neonato, admitindo o ambiente em que estão presentes, a família e o quadro clínico da criança, a história de vida do profissional, dentre os vários aspectos que constituem essa relação, sem deter-se apenas à proximidade do morrer, entretanto, também a abrangendo.

Os participantes expressaram como são seus olhares para esses bebês, significando-os em sua experiência vivida nos cuidados. Relatam que a criança sente o cuidado e a presença da mãe e refletem sobre o símbolo da criança para a família:

"Acredito que o bebê, apesar de ele não falar, ele sente, sente o cuidado, sabe que é a mãe que está ali, conhece" (Paloma).

"Mesmo que o indivíduo tenha meio quilo, porque ele é individuo, ele é um ser, é um pequeno ser, mas é um ser pra aquelas famílias...” (Laís).

“Há quem diga que não, mas eu penso que ele sente, não é, quando é permitido [pela família] a ele ir" (Clara).

Em todas as falas, compreende-se que os bebês foram colocados como sujeitos, que sentem e possuem um lugar na família. É fundamental considerar a condição de estabelecimento do apego da mãe com o feto, o que gera expectativas e receios desde o período da gestação, que aparece imbricado na relação com o neonato, ameaçado de morte, surgindo sentimentos antes desconhecidos pela mãe e que devem ser reconhecidos dentro perspectiva do CP. Torna-se clara a história dessa criança no mundo, não importa a brevidade do tempo ${ }^{(25)}$.

Os profissionais da UTIN devem incluir a família junto ao bebê em sua atenção à saúde, como preconizado pela filosofia dos $\mathrm{CP}$, visando um cuidado integral para o bebê e incluindo as necessidades multidimensionais que este apresenta e as demandas da família( ${ }^{(6)}$.

\section{As famílias dos bebês e a afetação dos profissionais}

Nessa categoria, as famílias dos bebês e a afetação dos profissionais são movimentos que explanam como os colaboradores experienciaram a família dos bebês durante a hospitalização e na situação de ter um bebê sem prognóstico. Apresenta-se como os profissionais experienciaram a relação com a família, como são afetados e como perceberam que deve ser essa relação. Foi descrito como acontece o contato com a família ou mesmo a ausência:

“... Inclusive, a gente passa a criar um vínculo com essa mãe e passa acompanhar e conhecer a história de um bebê, e lida com expectativas, com sonhos, com tanta coisa” (Gabriela).

"Não. Com a família, geralmente, a gente não tem contato [...] Exceto quando o pai ou a mãe estão do lado da incubadora e a gente precisa do prontuário e eles nos abordam, como a qualquer outro profissional de saúde, querendo saber do bebê, ai [a gente] dá uma olhadinha no prontuário e vê no que pode ajudar, mas as orientações, realmente, o médico e a enfermeira que são os mais adequados a dar orientação da terapêutica que a gente vê, não é? certo?" (Victória).

Os profissionais podem acessar as emoções da família quando facilitam um canal de comunicação fluente com eles ${ }^{(6)}$. A relação da equipe com a família é embasada pelas condições emocionais e pelo enfrentamento do profissional em lidar com o sofrimento da família na fala sobre a atuação e os procedimentos. Há uma diferença, na perspectiva fenomenológica, em falar sobre aspectos de forma teórica, sem implicar-se no que está sendo dito, e expressar sua experiência, o que acontece consigo em sua totalidade, movimento anterior ao pensamento proximidade do morrer. Quando o sofrimento é insuportável, acontece um distanciamento para com os familiares, seja como hostilidade, seja não envolvimento ${ }^{(30)}$.

Percebe-se que há uma dificuldade dos colaboradores em se colocarem, durante as entrevistas, expressarem sua percepção, seus sentimentos e emoções, estando sempre inclinados a serem reflexivos ${ }^{(11)}$.

A experiência vivida do profissional, englobando o teórico e a experiência propriamente dita, está entrelaçada ao encontro entre ele e a família. Com a ótica da humanização articulada à fenomenologia, essa relação é pautada no reconhecimento da subjetividade de ambos os envolvidos. Há uma co-responsabilização no cuidado, em que existe uma autonomia e produção de saúde do familiar, e compete ao profissional promover essa perspectiva, estando atento às barreiras para tal encontro, desvelando possibilidades do seu modo de agir no cuidado ${ }^{(12)}$.

$\mathrm{Na}$ atuação dos profissionais junto às famílias de bebês internados em UTIN, foram apresentadas como ações: inclusão das famílias no cuidado, promoção do contato da família com o bebê, atividades lúdicas (recorte e colagem, miçangas, desenhos, etc) e suporte à família:

"Porque logo no começo, quando estava, quando estava assim... mais grave não, mas assim... quando dava pra ela trocar a fraldinha dela, né, segurar a dieta, eu tentava incluir ela nos cuidados, ela já ficava com a nenenzinha dela nos braços, 
mesmo estando entubada, então a gente tenta fazer esse - não só eu, mas a equipe toda da UTI - tenta fazer esse vínculo, estreitar esse vínculo da mãe com o bebezinho, mesmo sendo um bebezinho que não era viável” (Samile).

"[...] aí, ela dizia que estava chateada, que o neném tinha piorado, mas não era aquela pessoa que gostava de falar; a gente trazia atividade [recurso terapêtico desenvolvido pela terapeuta ocupacional] pra ela fazer, ela fazia todas as atividades, todas. Ela ia atrás de mim em todos os lugares pra fazer as atividades [...]” (Jasmim).

A inserção dos pais no cuidado e o incentivo a convivência com o bebê facilita a relação pais-filhos, diminuindo o sofrimento e trazendo benefícios para o bebê, para a família e para a equipe, que inclusive compartilha a responsabilidade dos cuidados $^{(6)}$.

\section{O atravessamento da morte na experiência vivida dos profissionais}

Essa experiência retrata a presença na hora da morte do bebê, passando pela forma de lidar com a morte, até o reconhecimento da necessidade de se trabalhar para o enfrentamento da situação.

Nos trechos abaixo, os profissionais expressam a experiência de estarem presentes e acompanharem esse momento:

"Foi muito triste. Foi triste, porque eu estava vendo ali que não tinha volta, não tinha volta, que estava muito grave [...] que foi tentado, foi tentado muita coisa, na reanimação e tudo, mas ela não voltou... Sensação de tristeza mesmo, que pena” (Ana).

“Ah, foi terrível, porque assim, sabendo do envolvimento, ela [mãe do bebê] era uma pessoa difícil, mas não é porque ela era uma pessoa difícil que ela não amasse o filho dela, ela não sofreria, foi assim uma cena que ficou na minha cabeça muitos anos já, dela balançando aquele neném morto [...]” (Jasmim).

Os profissionais se envolvem em sua relação com o paciente e sentem a morte dele. A finitude do bebê é considerada ainda mais difícil de lidar que a do adulto, devido à conotação de tragédia pela brevidade do tempo de vida ${ }^{(24)}$.

Nota-se, pelas falas dos entrevistados, como foi mobilizador experienciar a morte do bebê, o que pode desencadear um conflito por sentir essa dor e não saber como se posicionar, pois informaram que são ensinados, desde o início da formação, a não estabelecer vínculo, sendo necessário validar as emoções deles. A forma de lidar com a morte está entrelaçada a três dimensões: a história pessoal (mortes que já vivenciou, perdas sentidas e processos de lutos anteriores); a cultura (representações de morte, espaço para expressão da dor e como o luto é visto); e a formação acadêmica e capacitação profissional ${ }^{(30)}$.

Foi também colocada a importância da sensibilidade presente nesse processo:

“[...] e, aí, eu também não quero perder a coisa mesmo estando sentindo isso, porque eu acho que é importante, também, assim... não quero nem naturalizar, dizer "ah, com tempo, isso vai ficar natural”. Não, não é assim, eu acho que inclusive, até como forma de estar ali perto do outro, é você não perder essa sensibilidade mesmo assim, da coisa da sensibilidade de alguma forma estar compreendendo aquele momento" (Gabriela).

"[...] mas eu acho que como profissional a gente tem que trabalhar essa questão na gente, pra ficar, não se tornar intolerante, e sim, mas mais um bebê que, assim, fatalmente vai, mas a gente sente a perda, mas a gente vai trabalhando essa questão e tudo[...]" (Ana).

A implicação no sentir associa-se à criação de vínculos dos profissionais com os neonatos, pois conhecem a história e a família da criança como base de segurança para desempenhar a assistência enquanto investimento de vida, mas, também, no momento do óbito. Para a humanização e a integralidade no cuidado ao bebê, os profissionais devem englobar o processo de morrer na prática da UTIN ${ }^{(24)}$.

Surgiu a dimensão de desenvolver recursos para sustentar o enfrentamento da morte sem distanciar-se dos sentimentos e banalizar a situação. Foi questionada a necessidade de se trabalhar para atuar com a morte:

“... porque a morte é sempre um momento de luto, não é? De ruptura, ela é dura, não tem morte fácil, não é? (pausa) Mas que, pelo menos, ela seja um pouco menos dura, um pouco mais fácil, e que ela seja entendida de tal forma, que as famílias não... (pausa) não, consigam demonstrar amor, consigam demonstrar carinho, consigam... (pausa) que isso não seja algo tão, (pausa) tão pouco palpável” (Laís).

“... porque você tem que dar espaço para o outro viver o luto e, se você não trabalhar o seu, você não dá espaço para outro, não é? Você interrompe, pelas suas angústias, pelo seu medo. Como é que o outro vai reagir, porque você não consegue lidar" (Clara).

Através da fenomenologia, admite-se a noção de seres mundanos, sem separação entre o interior e o exterior, havendo um entrelaçamento nas experiências dos profissionais, do bebê e da família ${ }^{(11)}$. O profissional deve examinar suas reações, como sua expressão está presente no paciente e se interfere no processo dele, prisma que promove um maior crescimento e amadurecimento para o próprio profissional ao olhar a si mesmo ${ }^{(23)}$. 
A noção de morte intrínseca na vida permite o entendimento dessa angústia com a finitude que é inerente ao ser. Não negar esse estranhamento facilita o lidar com processo de morrer, a partir da ampliação do olhar para todos os aspectos que envolvem esse processo, como a cultura, a história de vida, os valores morais, dentre outros ${ }^{(26)}$.

Em duas entrevistas foram explicitadas formas de a morte ser trabalhada para que os profissionais estejam fortalecidos e tenham autossuporte para lidar com ela:

"Bom, eu já fiz terapia; agora mesmo, eu não estou fazendo, mas eu já fiz terapia, já trabalhei várias vezes antes os lutos
mesmo com perdas de entes queridos" (Clara).

"[...] então assim, é, eu inclusive acho que eu tenho até que me preparar mais profissionalmente, não é, pra poder estar contribuindo de uma forma mais qualitativa, porque está sendo, acho, que uma das questões mais difíceis hoje, enquanto profissional, estar lidando com essas situações assim [...]” (Gabriela).

A filosofia dos CPs aponta como primordial trabalhar essa temática com os profissionais atuantes no contexto a partir de grupos discussão e de apoio, viabilizando expressão de sentimentos e dúvidas ${ }^{(6)}$, como também a modalidade de plantão psicológico, por constituir-se de um atendimento psicológico propício para os momentos de crise. Também são indicadas atividades de lazer visando a aproximação interpessoal da equipe e construção de relações de amizades ${ }^{(30)}$.

Entende-se a necessidade de se discutir mais esse tema, o desconhecido que é a dimensão da morte e a dor de vivenciar a vida ser interrompida ${ }^{(24)}$, principalmente quando se trata de cuidados de final de vida de um $\mathrm{RN}^{(9)}$.

Quando se admite o morrer como uma fase da vida, permite-se a integração do CP dentro dos níveis de atenção à saúde, fazendo-se necessário inseri-lo como uma forma de cuidado e assistência, intencionando a promoção da saúde e a prevenção de agravos com procedimentos invasivos e dolorosos ${ }^{(31)}$. A saúde coletiva visa um olhar ampliado para o processo saúde-doença, com o conceito de ser integral ${ }^{(12)}$, o que corrobora a filosofia do CP.

Compreende-se que um dos pilares para impulsionar o CP na neonatologia é associá-lo à promoção de saúde, pois esta é o primórdio de toda assistência. Trata-se de propiciar o bem-estar do paciente, seja qual for sua condição clínica. Faz-se necessário direcionar maior atenção a esse campo da saúde coletiva para superar a problemática dos malefícios que ocorrem com a tecnologização da saúde, valorizando o sujeito, sua família e os profissionais.

Por fim, entende-se que a experiência vivida pelos profissionais de saúde é infinita de possibilidades, bem como o CP é um campo de assistência amplo, que problematiza diversos aspectos da prática da neonatologia, e este estudo não consegue abranger toda essa complexidade, sendo este seu limite. Ressalta-se a importância de maiores aprofundamentos sobre essa assistência, com desenvolvimento de pesquisas para embasar a prática e para ampliar o acesso da filosofia no campo da neonatologia desde a formação dos profissionais de saúde.

\section{CONCLUSÃO}

Foi possível identificar, nas falas dos participantes da presente pesquisa, práticas condizentes com a proposta paliativa em alguns casos. Percebe-se que, mesmo sem o programa de cuidados paliativos na instituição, existe a iniciativa de realizar uma prática que se aproxima desses cuidados, principalmente ao buscar conforto para o bebê e maior inclusão da família, o que já mostra sensibilização para tal perspectiva.

Os desafios foram descritos como dificuldade de admitir a morte do bebê. As experiências vividas pelos profissionais de saúde na Unidade de Terapia Intensiva Neonatal (UTIN) apareceram com sua multiplicidade de diferenças, a partir da história de vida de cada um. Como semelhança, os relatos de quão mobilizador é cuidar do bebê na UTIN, devido ao medo da morte iminente ser tão próximo do nascimento. Surgiram os sentimentos de apego e tristeza, emergentes durante o cuidar; a percepção do bebê como um sujeito e pertencente a uma família; e o mecanismo de negação da condição da criança.

Os profissionais explanaram sobre suas relações com familiares. Para alguns, o envolvimento com a família demonstra interesse em conhecer a história e para outros, o distanciamento, que foi compreendido como forma de evitar o sofrimento. Afirma-se o estabelecimento de vínculos e a validação da expressão dos profissionais como importantes nos cuidados paliativos, o que deve ser discutido desde o percurso acadêmico, sendo dado suporte aos profissionais para reconhecerem suas necessidades nesta implicação. Na expressão das suas experiências, os participantes trouxeram a morte como um evento difícil de vivenciar, com sensação de tristeza e perda, e a necessidade do autocuidado para enfrentar esse momento, bem como preparação profissional para tal.

\section{REFERÊNCIAS}

1. Brasil. Ministério da Saúde. Portaria n ${ }^{\circ}$ 930, de 10 de maio de 2012. Define as diretrizes e objetivos para a organização da atenção integral e humanizada ao recém-nascido grave ou potencialmente grave e os critérios de classificação e habilitação de leitos de Unidade Neonatal no âmbito do Sistema Único de Saúde (SUS). Diário Oficial [da] República Federativa; Brasília; 2012 Maio 10 [acesso em 2015 Jul 20]. Disponível em: http://bvsms.saude.gov.br/bvs/saudelegis/gm/2012/ prt0930_10_05_2012.html 
2. Barros FC, Matijasevich A, Requejo JH, Giugliani E, Maranhão AG, Monteiro CA, et al. Recent trends in maternal, newborn, and child health in Brazil: progress toward Millennium Development Goals 4 and 5. Am J Public Health. 2010;100(10):1877-89.

3. Kenner C, Press J, Ryan D. Recommendations for palliative and bereavement care in the NICU: a family-centered integrative approach. J Perinatol. 2015; 35(Suppl 1):S19-23.

4. Ministério da Saúde (BR), Coordenação-Geral de Informação e Análise Epidemiológica. Painel de monitoramento da mortalidade infantil e fetal. 2017 [acesso em 2017 nov 10]. Disponível em: http://svs.aids.gov.br/dashboard/mortalidade/ infantil.show.mtw

5. Lansky S, Friche AAL, Silva AAM, Campos D, Bittencourt DAS, Carvalho ML, et al. Pesquisa Nascer no Brasil: perfil da mortalidade neonatal e avaliação da assistência à gestante e ao recém-nascido. Cad Saúde Pública. 2014;30(Supl):S192-S207.

6. Barbosa SMM, Lima e Souza J, Bueno M, Sakita NK, Bussotti EA. Particularidades em cuidados paliativos: período neonatal. In: Conselho Regional de Medicina do Estado de São Paulo. Cuidado paliativo. São Paulo: Conselho Regional de Medicina do Estado de São Paulo; 2008. p. 139-52.

7. Marçola L, Barbosa SMM, Zobolia I, Polastrinia RTV, Ceccon MEJ. Análise dos óbitos e cuidados paliativos em uma unidade de terapia intensiva neonatal. Rev Paul Pediatr. 2017;35(2):125-9.

8. Catlin A, Carter B. Creation of a neonatal end-of-life palliative care protocol. J Perinatol. 2002;22(3):184-95.

9. Bhatia J. Palliative Care in the fetus and newborn. J Perinatol. 2006;26 Suppl 1:S24-6.

10. Kilcullen M, Ireland S. Palliative care in the neonatal unit: neonatal nursing staff perceptions of facilitators and barriers in a regional tertiary nursery. BMC Palliative Care. 2017; 16(32):1-12.

11. Merleau-Ponty M. Fenomenologia da percepção. São Paulo: Martins Fontes; 2006.

12. Melo AKS. Lebenswelt: para um resgate da(s) fenomenologia(s) no campo Saúde Coletiva [tese]. Fortaleza: UECE/UFC/ UNIFOR; 2014.

13. Gomes AMA, Paiva ED, Valdés MTM, Frota MA, Albuquerque CM. Fenomenologia, humanização e promoção da saúde: uma proposta de articulação. Saúde Soc. 2008;17(1):143-52.

14. Oliveira NF. Terminalidade em unidade de terapia intensiva pediátrica e neonatal: condutas médicas que antecedem o óbito em hospital de referência no nordeste brasileiro [dissertação]. Fortaleza: Universidade Federal do Ceará; 2011.

15. Keele L, Keenan HT, Sheetz J, Bratton SL. Differences in characteristics of dying children who receive and do not receive palliative care. Pediatrics. 2013;132(1):72-8.

16. Brasil. Ministério da Saúde. Portaria $n^{0} 1.130$, de 5 de agosto de 2015. Institui a Política Nacional de Atenção Integral à Saúde da Criança (PNAISC) no âmbito do Sistema Único de Saúde (SUS) [acesso em 2017 Nov 28]. Disponível em: http:// bvsms.saude.gov.br/bvs/saudelegis/gm/2015/prt1130_05_08_2015.html

17. Minayo CS. Análise qualitativa: teoria, passos e fidedignidade. Ciênc Saúde Colet. 2012;17(3):621-6.

18. Bosi MLM. Pesquisa qualitativa em saúde coletiva: panorama e desafios. Ciênc Saúde Colet. 2012;17(3):575-86.

19. Empresa Brasileira de Serviços Hospitalares - EBSERH. Maternidade Escola Assis Chateaubriand. 2017 [acesso em 2017 Nov 10]. Disponível em: http://www.ebserh.gov.br/web/meac-ufc/inicio

20. Moreira V. O método fenomenológico de Merleau-Ponty como ferramenta crítica na pesquisa em psicopatologia. Psicol Reflex Crít. 2004;17(3):447-56.

21. Amatuzzi MM. Etapas do processo terapêutico: um estudo exploratório. Psicol Teor Pesqui. 1993;9(1):1-21.

22. Mendes J, Silva LJ, Santos MJM. Cuidados paliativos neonatais e pediátricos para Portugal - um desafio para o século XXI. Acta Ped Port. 2012;43(5):218-22.

23. Soares C, Rodrigues M, Rocha G, Martins A, Guimarães H. Fim de vida em neonatologia: integração dos cuidados paliativos. Acta Ped Port. 2013;26(4):318-26.

24. Menin GE, Pettenon KP. Terminalidade da vida infantil: percepções e sentimentos de enfermeiros. Rev Bioét. 2015;23(3):608-14.

25. Carter BS. More than medication: perinatal palliative care [editorial]. Acta Pediátrica. Editorial. 2016;105: 1255-6. 
26. Mumford J. 'To arrive where we started, and know the place for the first time': Heidegger, phenomenology, the way human beings first appear in the world, and fresh perspectives on the abortion debate. New Bioeth. 2013;19(2):72-83.

27. Willems DL, Verhagen E, Wijlick EV. Infants' best interests in end-of-life care for newborns. Pediatrics. 2014;134(4):11638.

28. Santana JCB, Dutra BS, Carlos JMM, Barros JKA. Ortotanásia nas unidades de terapia intensiva: percepção dos enfermeiros. Rev Bioét. 2017;25(1):158-67.

29. Kübler-Ross E. Sobre a morte e o morrer. São Paulo: Martins Fontes; 2011.

30. Kovács MJ. Sofrimento da equipe de saúde no contexto hospitalar: cuidando do cuidador profissional. Mundo Saúde. 2010;34(4):420-9.

31. Brasil. Ministério da saúde. Portaria n 4.279 , de 30 de dezembro de 2010. Estabelece diretrizes para a organização da Rede de Atenção à Saúde no âmbito do Sistema Único de Saúde (SUS) [acesso em 2017 Nov 28]. Disponível em: http://bvsms. saude.gov.br/bvs/saudelegis/gm/2010/prt4279_30_12_2010.html

\section{Endereço do primeiro autor:}

Ana Maria Ferreira Alves

Secretaria Adjunta da Política de Atenção Primária e Vigilância em Saúde

Av. dos Holandeses, qd 07/3

Bairro: Calhau

CEP: 65071-380 - São Luís - MA - Brasil

E-mail: anamariaferreiraalves@gmail.com

\section{Endereço para correspondência:}

Anna Karynne Melo

Universidade de Fortaleza - UNIFOR

Programa de Pós Graduação em Saúde Coletiva

Av. Washington Soares, 1321

Bairro: Edson Queiroz

CEP: 60811-905 - Fortaleza - CE - Brasil

E-mail: karynnemelo@unifor.br 